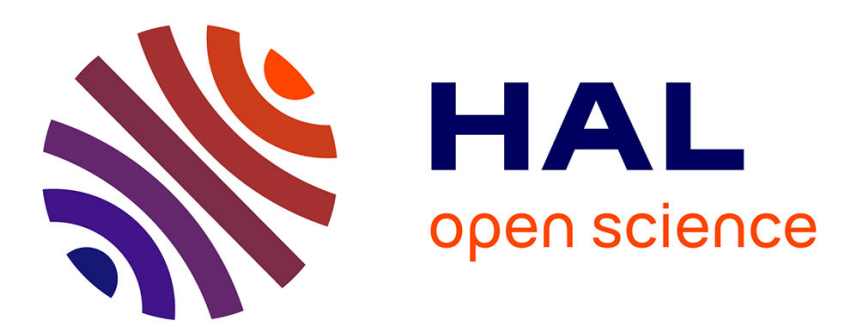

\title{
Elementary Subdomain Technique for Magnetic Field Calculation in Rotating Electrical Machines with Local Saturation Effect
}

Lazhar Roubache, Kamel Boughrara, Frédéric Dubas, Rachid Ibtiouen

\section{To cite this version:}

Lazhar Roubache, Kamel Boughrara, Frédéric Dubas, Rachid Ibtiouen. Elementary Subdomain Technique for Magnetic Field Calculation in Rotating Electrical Machines with Local Saturation Effect. COMPEL: The International Journal for Computation and Mathematics in Electrical and Electronic Engineering, 2018, 28 (1), pp.24 - 25. hal-02130122

\section{HAL Id: hal-02130122 \\ https://hal.science/hal-02130122}

Submitted on 15 May 2019

HAL is a multi-disciplinary open access archive for the deposit and dissemination of scientific research documents, whether they are published or not. The documents may come from teaching and research institutions in France or abroad, or from public or private research centers.
L'archive ouverte pluridisciplinaire HAL, est destinée au dépôt et à la diffusion de documents scientifiques de niveau recherche, publiés ou non, émanant des établissements d'enseignement et de recherche français ou étrangers, des laboratoires publics ou privés. 
DOI: 10.1108/COMPEL-11-2017-0481, COMPEL - The International Journal for Computation and Mathematics in Electrical and Electronic Engineering

\title{
Elementary Subdomain Technique for Magnetic Field Calculation in Rotating Electrical Machines with Local Saturation Effect
}

\author{
Lazhar Roubache $^{1}$, Kamel Boughrara $^{1}$, Frédéric Dubas $^{2}$, Rachid Ibtiouen $^{1}$ \\ ${ }^{1}$ Ecole Nationale Polytechnique (LRE-ENP), Rue des Frères Oudek, Hassan Badi, B.P. 182, El-Harrach, 16200, Alger, Algérie \\ ${ }^{2}$ Département ENERGIE, FEMTO-ST, CNRS, Univ. Bourgogne Franche-Comté, Belfort, France
}

\section{ABSTRACT}

Purpose - The most significant point to be introduced in the subdomain technique (i.e., based on the formal resolution of Maxwell's equations applied in subdomain) is the local saturation effect. In this paper, the author presents a novel contribution on improving of this two-dimensional (2-D) technique in polar coordinates by focusing on the local saturation. Design/methodology/approach - The rotor and the stator regions are divided into elementary subdomains (E-SDs) which are characterized by general solutions to the first harmonic of magnetostatic Maxwell's equations. These E-SDs are connected in the two directions (i.e., $r$ - and $\theta$-edges). Newton-Raphson (NR) iterative algorithm is used for nonlinear magnetic field analysis. Findings - The proposed model is relevant for different types of rotating electrical machines, as an example the semi-analytical model has been implemented for spoke-type permanent-magnet (PM) machines (STPMMs).The magnetic field calculations have been performed for nonlinear $B(H)$ curve and compared to nonlinear finite-element method (FEM) predictions. The semianalytic results are in good agreement with those obtained numerically, considering both amplitude and waveform.

Originality/value - A new model for full prediction of magnetic field in the rotating electrical machines with the local saturation effect is presented.

\section{INTRODUCTION}

In electrical machines design and optimization tools, the most influential parameters are the accuracy compared to test results and the computation time consumed. As it is well known, the numerical methods (i.e., the finite-element, finite-difference or boundaryelements analysis) [1]-[2] are very effective with the ability to take various geometries and several parameters such as nonlinear and nonhomogeneous materials, eddy-current, transient and steady state simulations. In other hand, many different works have been oriented towards the proposal and improvement of hybrid numerical methods [3]-[4] and (semi-)analytical models [5]-[17], which are fast and adapted to the first design steps. Subdomains technique is one of the most recent semi-analytical methods for magnetic field prediction and electromagnetic performance calculation in electrical machines. This method is based principally by the division of the machines into SDs and defined the solution of magnetostatic Maxwell's equations for each SD.

The general solutions are deduced by considering the interfaces conditions (ICs) between different regions. The most significant assumption in this technique is that the iron parts are considered to be infinitely permeable so that the global/local saturation effect is neglected. Indeed, this assumption leads to homogeneous boundary condition (BCs) in non-periodic regions (e.g., rotor/stator slot). The global solutions are obtained by considering only $\theta$-edges ICs. Until last year, this technique is used in the modeling of several types of electrical machines such as [5]-[8] for PM synchronous machines, [9]-[11] for solid or cage rotor induction motors, and [12][13] for reluctance machines. Some comprehensive reviews of magnetic field prediction in electrical machines using SD technique can be found in [5], [14], and [18]-[19].

Give up nonhomogeneous Neumann BCs and the iron consideration in magnetic field prediction using SD technique in 
Cartesian coordinate appeared for the first time by Dubas et al. [14], in which the connection is performed in both directions (i.e., $x$ - and $y$-edges). In [15], Roubache et al. proposed SD technique taking into account the iron relative permeability in the STPMMs. In this paper, the $r$-edges ICs are performed using Taylor series expansion. Recently, a novel exact approach for airor iron-cored coil modeling in polar coordinates is proposed by [16]. In [17], this approach is extended to synchronous electric machines modeling. Herein, the general solutions of Maxwell's equations are deduced by applying the principle of superposition and the SDs connections are carried out in $\theta$-edges directions using Fourier series expansion, and in $r$-edges directions using new proposed series expansion.

The aim of this paper is to extend the proposed model in [16]-[17] for full prediction of magnetic field in the rotating electrical machines with the local saturation effect, and introducing for the first time NR iterative algorithm in nonlinear magnetic field analysis using SD technique.

The first part of this paper presents the principles of the proposed E-SD technique. Then, a more detailed for magnetic field solutions in the various regions and the adaptation of NR iterative algorithm with the proposed technique are done. Finally, the obtained results from the developed semi-analytical model are compared to those found by FEM [20].

\section{METHODOLOGY}

The aim of this paper is to propose a general semi-analytical model for full prediction of magnetic field in the rotating electrical machines. This model takes into account the local saturation effect and gives the magnetic field distribution in all machine regions (e.g., PMs, slots, teeth, yoke...).

As an example the proposed E-SD technique coupled with NR iterative algorithm for nonlinear magnetic field analysis has been implemented for STPMM [see Fig. 1]. However, it can be easily implemented for other types of electrical machines, this E$\mathrm{SD}$ technique in polar coordinates $(r, \theta)$ is formulated in magnetic vector potential $A_{z}$ with the following assumptions:

- the end-effects are neglected (i.e., that the magnetic variables are independent of $z$ );

- the stator slots/teeth, the rotor teeth and the PMs have radial sides;

- the current density has only one component along the $z$-axis;

- the electrical conductivities of materials are assumed to be null;

- the direction of PMs magnetization is supposed purely tangential, i.e., $\boldsymbol{M}=\left\{0, M_{\theta}, 0\right\}$;

- the E-SDs are considered as isotropic regions;

- the iron reluctivity is a function of the mean value of magnetic field $\bar{B}$ in each E-SD.

The main idea of the proposed model is to mesh the rotor and the stator regions into E-SDs [see Figs. 2.a-2.b]. Then, the general solution of magnetostatic Maxwell's equations is taking such as in [16]-[17]. However, the E-SDs must be small enough that the potential vector variation can be considered as not important. This approximation allows us to consider only the first radial and tangential harmonics, which makes the desired accuracy related to the number of E-SDs instead of the harmonics number.

It should be noted that the non-saturated regions (e.g., stator slots) are meshed for a programming reason. In fact, this rends the adjacent E-SDs have the same spatial frequency and the obtained equations from the ICs between the different E-SDs will have the same form [see Appendix B]. Moreover, using the description given in this paper, one can program this model by associate the E-SDs by more than one harmonic (e.g., two or three harmonics). However, as the aim is to consider the local 
saturation, the E-SDs should be small and the high harmonics will be useless. A comparison between the case of one harmonic and three harmonics is given in Section $\mathbf{V}$.

The mesh in this model is done with simple algorithm by devising the rotor and the stator region in $r$-and $\theta$-directions. As examples, a comparison between three different meshes is done in Section $\mathbf{V}$ :

- Mesh 1 (M1) : only the stator slots are divided by three in $\theta$-direction which give 72 E-SDs in the stator and 24 ESDs in the rotor

- Mesh 2 (M2) : the rotor teeth are divided by six in $\theta$-direction and the stator slots/teeth and the PMs are divided by three in $r$ - and $\theta$-directions which give $180 \mathrm{E}-\mathrm{SDs}$ in the stator and $180 \mathrm{E}-\mathrm{SDs}$ in the rotor

- Mesh 3 (M3) : the stator/rotor slots/teeth/PMs are divided by six in $r$ - and $\theta$-direction which give 576 E-SDs in the stator and 384 E-SDs in the rotor

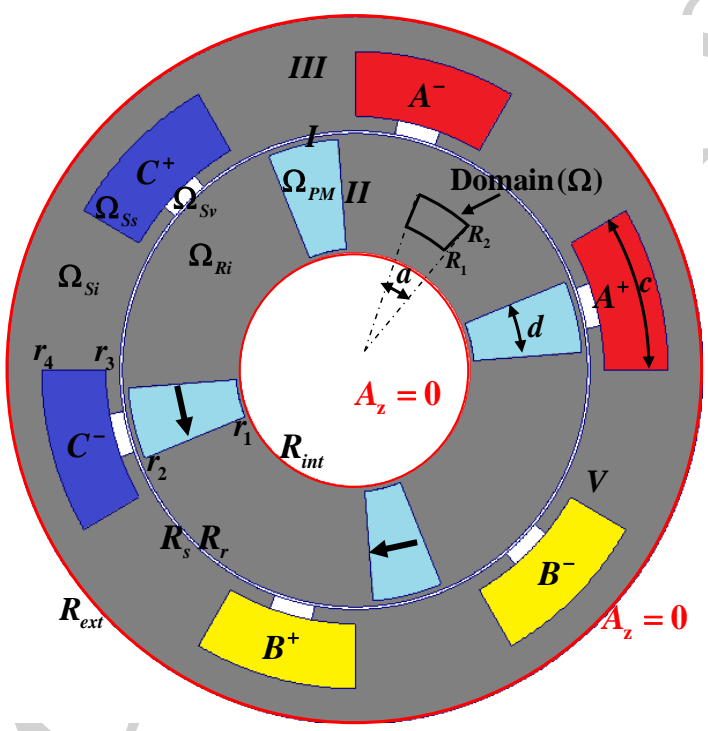

Fig. 1. Examples of STPMM

The general solution of magnetostatic Maxwell's equations considering only the first radial and tangential harmonics in each domain $(\Omega)$ can be written as [16]-[17]

$$
A_{z}(r, \theta)=A_{z}^{\theta}+A_{z}^{r}+A_{z}^{p}
$$

where

$$
\begin{aligned}
& A_{z}^{\theta}=\xi_{1}+\xi_{2} \ln (r)+\left(\xi_{3}\left(\frac{r}{R_{2}}\right)^{\frac{\pi}{a}}+\xi_{4}\left(\frac{r}{R_{1}}\right)^{-\frac{\pi}{a}}\right) \cos \left[\frac{\pi}{a}\left(\theta-\alpha+\frac{a}{2}\right)\right] \\
& A_{z}^{r}=\left\{\begin{array}{l}
\xi_{5} \sinh \left[\frac{\pi}{\ln \left(R_{2} / R_{1}\right)}\left(\theta-\alpha+\frac{a}{2}\right)\right] \\
+\xi_{6} \sinh \left[\frac{\pi}{\ln \left(R_{2} / R_{1}\right)}\left(\theta-\alpha-\frac{a}{2}\right)\right]
\end{array}\right\} \frac{\sin \left[\frac{\pi \ln \left(r / R_{1}\right)}{\ln \left(R_{2} / R_{1}\right)}\right]}{\sinh \left[\frac{\pi}{\ln \left(R_{2} / R_{1}\right)} a\right]}
\end{aligned}
$$




$$
A_{z}^{p}= \begin{cases}-\mu_{0} M_{\theta}^{j} r & \text { if } \Omega \in \Omega_{P M}^{j} \\ -\mu_{0} \frac{1}{4} J_{z}^{i} r^{2} & \text { if } \Omega \in \Omega_{S s}^{i} \\ 0 & \text { if } \Omega \in \Omega_{R i} \cup \Omega_{S i} \cup \Omega_{S v}\end{cases}
$$

where $M_{\theta}^{j}=(-1)^{j} \cdot B_{r m} / \mu_{0}$ with $j$ varying from 1 to $2 p$ poles in which $B_{r m}$ is the remanent flux density of PMs, and $J_{z}^{i}$ is the current density in the $i^{\text {th }}$ stator slot with $i$ vary from 1 to $Q_{s}$ in which $Q_{s}$ represents the number of stator slots, $\Omega_{P M}^{j}$ is the $j^{\text {th }}$ PM region, $\Omega_{S s}^{i}$ the $i^{\text {th }}$ stator slot, $\Omega_{R i}$ and $\Omega_{S i}$ are the iron regions in the rotor and the stator regions respectively, $\Omega_{S v}$ is the stator isthmus-opening region, $\left\{R_{1}, R_{2}, \alpha, a\right\}$ are the main dimension of $\Omega$, and $\left\{\xi_{1}, \xi_{2}, \xi_{3}, \xi_{4}, \xi_{5}, \xi_{6}\right\}$ are its integration constants.

Each E-SD is characterized by absolute reluctivity in function of $\bar{B}$, this function is obtained from the nonlinear curve using the analytical model given in [21]:

$$
v(\bar{B})=\frac{1}{\mu_{0}}\left[1-\frac{Q}{\sum_{q=1}^{Q}\left(\left(\bar{B} / m_{q}\right)^{n_{q}}+a_{q}^{n_{q}}\right)^{1 / n_{q}}}\right]
$$

where $\bar{B}$ is the mean value of field density in the E-SD [see Appendix C], $\mu_{0}$ is the vacuum permeability, and $q$ is an index and $\left\{m_{q}, n_{q}, a_{q}\right\}$ are the parameters to be optimized using genetic algorithm. The $B(H)$ and $v(\bar{B})$ curves used herein and their corresponding parameters are given in Appendix A. For the paramagnetic regions (i.e., $\Omega_{P M}^{j}, \Omega_{S S}^{i}$, and $\Omega_{S v}$ ), the reluctivity is defined as

$$
v(\bar{B})=\frac{1}{\mu_{0}}
$$

After defined the solutions in different regions (i.e., rotor, stator, and air-gap), the ICs between the various regions should be introduced to determine the integration constants. These ICs give nonlinear system equation [see Section III] which can be solved using NR iterative algorithm [see Section IV].

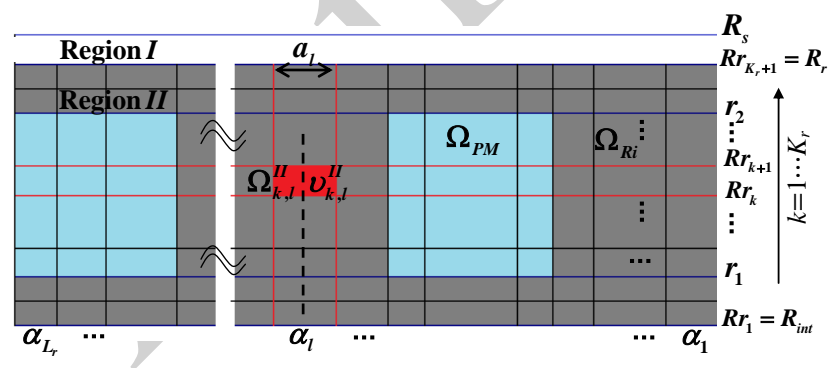

(a)

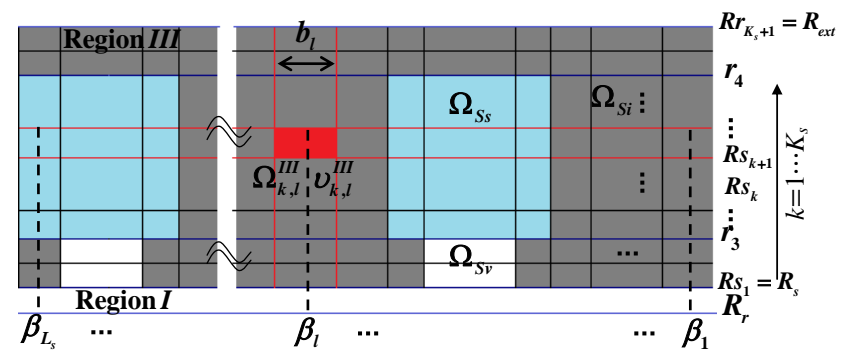

(b)

Fig. 2. Mesh generation of: (a) the rotor and (b) the stator.

\section{MAGNETIC FIELD SOLUTION}

In the proposed model the machine is divided into three regions. Fig. 1 shows the machines topologies where: i) Region I represents the air-gap, ii) Region II the rotor, and iii) Region III the stator. 
After meshing the stator and the rotor region into E-SDs, each E-SD is associated by inner and outer radii, position, opening width, and absolute reluctivity. The following sub-sections present the general solutions in each region.

\section{A. General solution of Laplace's equation in region I}

In the air-gap (i.e., Region I), which is an annular domain at $r \in\left[R_{r} ; R_{s}\right]$, the solution of Laplace's equation can be written as $[16]-[17]$

$$
\begin{aligned}
A_{z I}(r, \theta) & =A 1_{0}+A 2_{0} \ln (r) \\
& +\sum_{n=1}^{\infty}\left[A 1_{n}\left(\frac{r}{R_{s}}\right)^{n}+A 2_{n}\left(\frac{r}{R_{r}}\right)^{-n}\right] \sin (n \theta) \\
& +\sum_{n=1}^{\infty}\left[A 3_{n}\left(\frac{r}{R_{s}}\right)^{n}+A 4_{n}\left(\frac{r}{R_{r}}\right)^{-n}\right] \cos (n \theta)
\end{aligned}
$$

where $n$ is a positive integer, and $A 1_{0}-A 4_{n}$ are the integration constants in Region I.

The field vectors $\boldsymbol{B}=\left\{B_{r} ; B_{\theta} ; 0\right\}$ and $\boldsymbol{H}=\left\{H_{r} ; H_{\theta} ; 0\right\}$ in these regions are coupled by

$$
\boldsymbol{H}_{I}=\boldsymbol{B}_{I} / \mu_{0}
$$

\section{B. General Solution of Laplace's/Poisson's Equations in Region II}

The rotor region (i.e., Region II) is divided into E-SDs as it shown in Fig. 2(a). Each element $\Omega_{I I}^{k, l}$ is characterized by the parameters $\left\{A_{z I I}^{p k, l}, v_{I I}^{k, l}, \alpha_{l}, a_{l}, R r_{k}, R r_{k+1}\right\}$ where $A_{z I I}^{p k, l}$ is the particular solution, $v_{I I}^{k, l}$ is the absolute reluctivity, and $\left\{\alpha_{l}, a_{l}, R r_{k}, R r_{k+1}\right\}$ are the corresponding main dimension. The general solution of $A_{z}$ in this region can be written as [16]-[17]

$$
\begin{aligned}
& A_{z I I}^{k, l}=B_{1}^{k, l}+B_{2}^{k, l} \ln (r)+A_{z I I}^{p k, l} \\
& \cdots+\left(B_{3}^{k, l}\left(\frac{r}{R r_{k+1}}\right)^{\vartheta_{r l}}+B_{4}^{k, l}\left(\frac{r}{R r_{k}}\right)^{-\vartheta_{r l}}\right) \cos \left[\vartheta_{r l}\left(\theta-\alpha_{l}+\frac{a_{l}}{2}\right)\right] \\
& +\left\{\begin{array}{l}
B_{5}^{k, l} \sinh \left[\lambda_{r k}\left(\theta-\alpha_{l}+\frac{a_{l}}{2}\right)\right] \\
+B_{6}^{k, l} \sinh \left[\lambda_{r k}\left(\theta-\alpha_{l}-\frac{a_{l}}{2}\right)\right]
\end{array}\right\} \frac{\sin \left[\lambda_{r k} \ln \left(\frac{r}{R r_{k}}\right)\right]}{\sinh \left[\lambda_{r k} a_{l}\right]}
\end{aligned}
$$

where

$$
\lambda_{r k}=\frac{\pi}{\ln \left(R r_{k+1} / R r_{k}\right)} \text { and } \vartheta_{r l}=\frac{\pi}{a_{l}}
$$

The field vectors $\boldsymbol{B}=\left\{B_{r} ; B_{\theta} ; 0\right\}$ and $\boldsymbol{H}=\left\{H_{r} ; H_{\theta} ; 0\right\}$ in these regions are coupled by

$$
\boldsymbol{H}_{I I}^{k, l}= \begin{cases}v_{I I}^{k, l}\left(\boldsymbol{B}_{I I}^{k, l}-\mu_{0} \boldsymbol{M}^{j}\right) & \text { if } \Omega \in \Omega_{P M}^{j} \\ v_{I I}^{k, l} \boldsymbol{B}_{I I}^{k, l} & \text { if } \Omega \in \Omega_{R i}\end{cases}
$$




\section{General solution of Laplace's/Poisson's equations in region III}

The stator region (i.e., Region III) is divided into E-SDs as it shown in Fig. 2(b). Each element $\Omega_{I I I}^{k, l}$ is characterized by the parameters $\left\{A_{z I I I}^{p k, l}, v_{I I I}^{k, l}, \beta_{l}, b_{l}, R s_{k}, R s_{k+1}\right\}$ where $A_{z I I I}^{p k, l}$ is the particular solution, $v_{I I I}^{k, l}$ is the absolute reluctivity and $\left\{\beta_{l}, b_{l}, R s_{k}, R s_{k+1}\right\}$ are the corresponding main dimension. The general solution of $A_{z}$ in this region can be written as [16]-[17]

$$
\begin{aligned}
& A_{z I I I}^{k, l}=C_{1}^{k, l}+C_{2}^{k, l} \ln (r)+A_{z I I I}^{p k, l} \\
& \cdots+\left(C_{3}^{k, l}\left(\frac{r}{R s_{k+1}}\right)^{\vartheta_{s l}}+C_{4}^{k, l}\left(\frac{r}{R s_{k}}\right)^{-\vartheta_{s l}}\right) \cos \left[\vartheta_{s l}\left(\theta-\beta_{l}+\frac{b_{l}}{2}\right)\right] \\
& \cdots+\left\{\begin{array}{l}
\left.C_{5}^{k, l} \sinh \left[\lambda_{s k}\left(\theta-\beta_{l}+\frac{b_{l}}{2}\right)\right]\right) \sin \left[\lambda_{s k} \ln \left(\frac{r}{R s_{k}}\right)\right] \\
\left.+C_{6}^{k, l} \sinh \left[\lambda_{s k}\left(\theta-\beta_{l}-\frac{b_{l}}{2}\right)\right]\right\} \frac{\sinh \left[\lambda_{s k} b_{l}\right]}{}
\end{array}\right.
\end{aligned}
$$

where

$$
\lambda_{s k}=\frac{\pi}{\ln \left(R s_{k+1} / R s_{k}\right)} \quad \text { and } \quad \vartheta_{s l}=\frac{\pi}{b_{l}}
$$

The field vectors $\boldsymbol{B}=\left\{B_{r} ; B_{\theta} ; 0\right\}$ and $\boldsymbol{H}=\left\{H_{r} ; H_{\theta} ; 0\right\}$ in these regions are coupled by

$$
\boldsymbol{H}_{I I I}^{k, l}=v_{I I I}^{k, l} \boldsymbol{B}_{I I I}^{k, l}
$$

It should be noted that the $r$ - and $\theta$-components of $\boldsymbol{B}$ are deduced from $A_{z}$ by

$$
B_{r \bullet}=\frac{1}{r} \frac{\partial A_{z_{\bullet}}}{\partial \theta} \text { and } B_{\theta_{\bullet}}=-\frac{\partial A_{z \bullet}}{\partial r} \text { with } \bullet=I, I I, I I I
$$

\section{ICS AND NR ITERATIVE ALGORITHM}

The integration constants in (7), (9), and (11) can be determined by solving the following nonlinear system equations obtained from the ICs between the various regions [see Appendix B], viz.,

$$
f(X)=[M(X)] X+Y=0
$$

where

$$
\begin{aligned}
& M(X)=\left[\begin{array}{ccc}
\Lambda^{11} & \Lambda^{12} & \Lambda^{13} \\
0 & \Lambda^{22} & 0 \\
0 & 0 & \Lambda^{33} \\
\Lambda^{41} & \Lambda^{42}\left(b^{\text {rotor }}\right) & \Lambda^{43}\left(c^{\text {stator }}\right) \\
0 & \Lambda^{52}\left(b^{\text {rotor }}\right) & 0 \\
0 & 0 & \Lambda^{63}\left(c^{\text {stator }}\right)
\end{array}\right] \\
& X=\left[\begin{array}{lll}
\mathrm{a}^{\text {air }} & b^{\text {rotor }} & c^{\text {stator }}
\end{array}\right]^{T}
\end{aligned}
$$




$$
\begin{aligned}
& Y=\left[\begin{array}{llllll}
\Gamma^{1} & \Gamma^{2} & \Gamma^{3} & \Gamma^{4} & \Gamma^{5} & \Gamma^{6}
\end{array}\right] \\
& \mathrm{a}^{\text {air }}=\left[\begin{array}{llll}
A 1_{0} \cdots A 1_{N} & A 2_{0} \cdots A 2_{N} & A 3_{1} \cdots A 3_{N} & A 4_{1} \cdots A 4_{N}
\end{array}\right]^{T} \in \Re^{(4 N+2) \times 1} \\
& b^{\text {rotor }}=\left[\begin{array}{lllll}
B_{1}^{1,1} \cdots B_{6}^{1,1} & B_{1}^{1,2} \cdots B_{6}^{1,2} \cdots B_{1}^{K_{r}, L_{r}} \cdots B_{6}^{K_{r}, L_{r}}
\end{array}\right]^{T} \in \mathfrak{R}^{\left(6 K_{r} L_{r}\right) \times 1}
\end{aligned}
$$

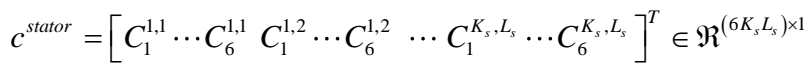

It should be noted that the first three lines of sub-matrices in the matrix M correspond to ICs of $A_{z}$ where the equations are independent to the absolute reluctivity of materials. However, the other sub-matrices are corresponding to ICs of $H_{/ /}$at surface. These later are depending to the absolute reluctivity of materials which are also related to the unknowns vector X.

The Jacobian matrix of $f(X)$ can be written for the $k^{\text {th }}$ iteration as

$$
J^{k}\left(X^{k}\right)=\left[M\left(X^{k}\right)\right]+[\Lambda] X^{k}
$$

where

$$
[\Lambda]=\left[\begin{array}{ccc}
0 & 0 & 0 \\
0 & 0 & 0 \\
0 & 0 & 0 \\
0 & \partial \Lambda^{42} / \partial b^{\text {rotor }} & \partial \Lambda^{43} / \partial c^{\text {stator }} \\
0 & \partial \Lambda^{52} / \partial b^{\text {rotor }} & 0 \\
0 & 0 & \partial \Lambda^{63} / \partial b^{\text {stator }}
\end{array}\right]
$$

The description of $\partial \Lambda^{\bullet} / \partial b^{\text {rotor }}$ and $\partial \Lambda^{\bullet} / \partial c^{\text {stator }}$ is given in Appendix $\mathbf{C}$.

Using the well-known NR iterative formula the solution at each iteration is given as:

$$
X^{k+1}=-J^{k} f^{k}+X^{k}
$$

where $J^{k}$ is the Jacobian matrix, and $f^{k}=\left[M\left(X^{k}\right)\right] X^{k}+Y$.

In order to improve the convergence, the nonlinear iteration was decelerated by applying an under relaxation factor $\varepsilon$ as follows:

$$
X^{k+1}=X^{k}+\varepsilon\left(X^{k+1}-X^{k}\right)
$$

The usual NR iterative algorithm can be obtained for $\varepsilon=1$. Herein, the value of $\varepsilon$ is changed according [22] in such a way to reduce the norm of residual vector $\|f\|$, where $\varepsilon$ is divided by two until the following condition is satisfied

$$
\left\|f^{k+1}\right\| \leq\left\|f^{k}\right\|
$$

The initial vector $X^{0}$ is defined as $X^{0}=-[M(0)]^{-1} Y$, and then the iterative procedure continues until the desired global convergence criteria $\left\|f^{k}\right\| /\|Y\| \leq 10^{-3}$ which is enough to make the residual vector $f^{k}$ negligible compared to the second member $Y$. Fig. 3 shows the flowchart for the NR iterative algorithm. 


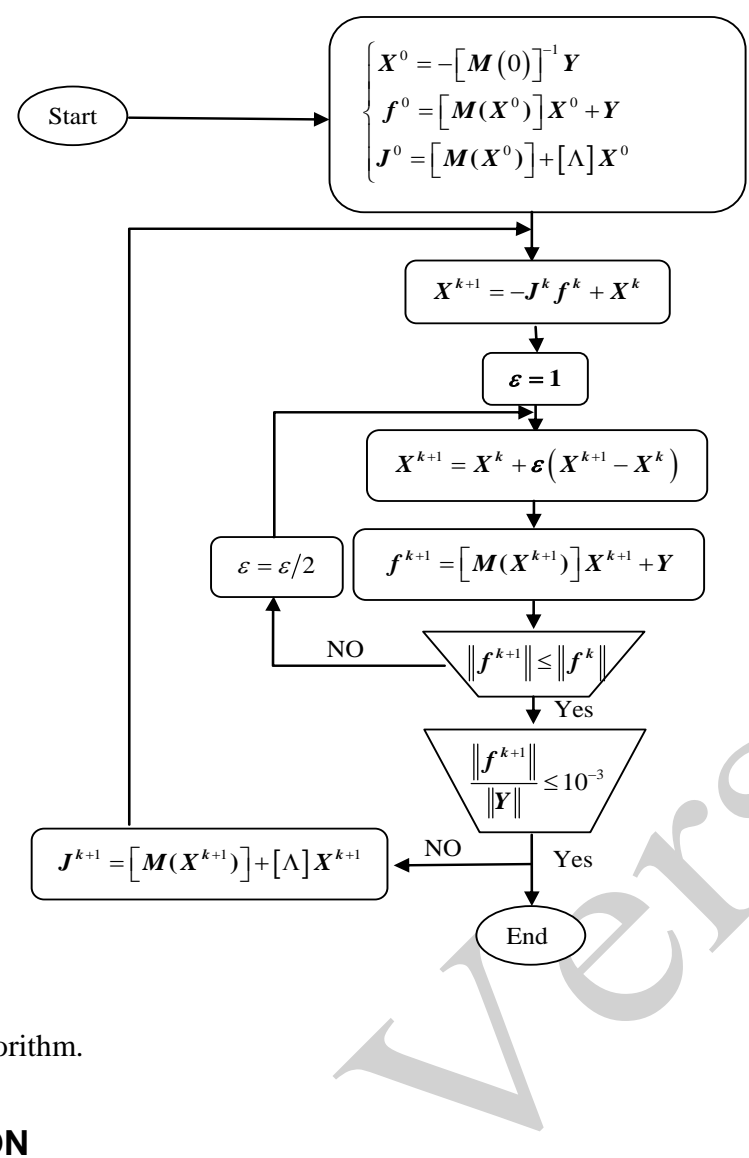

\section{RESULTS AND VALIDATION}

The developed semi-analytical method with the local saturation effect is used to determine the magnetic field in all regions of the machines. The main dimensions and parameters of the studied machine are given in Table I. Then, semi-analytic results are verified by FEM [20]. To find agreeable results, we have used sufficient maximum segments in arcs drawing and automatic mesh generation, which gives 17,708 nodes and 35,231 elements. The simulation consumes around 8 sec.

In Fig. 4, a comparison between the numerical results and the semi-analytical predictions for on load condition are shown in terms of magnitude of $\mathbf{B}$ in the middle of the air-gap (i.e., Region I) for three different meshes and tow case: i) one $r$ - and $\theta$-harmonic are associated for each E-SD and ii) three $r$ - and $\theta$-harmonics are associated for each E-SD. It can be seen that the semi-analytic model converge to the solution given by FEM however the time simulation become important for fin mesh (i.e., mesh (M3)). In the case of three harmonics per E-SD, the computation time augments nevertheless the accuracy don't affect so match, this refer to the local saturation of the iron which need the augmentation of the number of E-SDs more than the number of the harmonics. It should be noted that the RMS error is calculated as

$$
\text { Error }=\sqrt{\sum_{m=1}^{N_{p c}}\left(B_{I r, m}^{\text {Numeric }}-B_{I r, m}^{\text {Analytic }}\right)^{2} / N_{p c}}
$$

where $N_{p c}=500$ is the number of points along the tangential.

Figs. 5-7 present the $r$ - and $\theta$-components of $\mathbf{B}$ in the circles placed at the middle of the: i) air-gap ii) outer rotor bridge, and iii) stator yoke for on load condition. The results are good with agreeable error. The oscillation seen in Figs. 6a is explained by the nature of the solution proposed in the E-SDs which is sinus in terms of radial components. 
TABLE I. Parameters of studied machine.

\begin{tabular}{|c|c|c|}
\hline Symbol & Parameters & Value \\
\hline$B_{r m}$ & Remanent flux density of PMs & $1.2 T$ \\
\hline$\mu_{r m}$ & Relative permeability of PMs & 1 \\
\hline$N_{c}$ & Number of conductors per stator slot & 200 \\
\hline$I_{m}$ & Peak phase current & $5-20 A$ \\
\hline$Q_{s}$ & Number of stator slots & 6 \\
\hline$c$ & Stator slot-opening & $30 \mathrm{deg}$. \\
\hline$c_{r}$ & Stator isthmus-opening & $10 \mathrm{deg}$ \\
\hline$d$ & PM-opening & $18 \mathrm{deg}$ \\
\hline$p$ & Number of pole pairs & 2 \\
\hline$R_{\text {ext }}$ & Radius of the external stator surface & $67 \mathrm{~mm}$ \\
\hline$r_{4}$ & External radius of stator slot & $60.3 \mathrm{~mm}$ \\
\hline$r_{3}$ & Internal radius of stator slot & $48 \mathrm{~mm}$ \\
\hline$R_{s}$ & Radius of the internal stator surface & $45.3 \mathrm{~mm}$ \\
\hline$R_{r}$ & Radius of the external rotor surface & $44.8 \mathrm{~mm}$ \\
\hline$r_{2}$ & External radius of the PMs & $43.8 \mathrm{~mm}$ \\
\hline$r_{l}$ & Internal radius of the PMs & 23 \\
\hline$R_{\text {int }}$ & Radius of the rotor inner surface & $22 \mathrm{~mm}$ \\
\hline$L_{u}$ & Axial length & $63 \mathrm{~mm}$ \\
\hline$\Omega$ & Mechanical pulse of synchronism & $1,500 \mathrm{rpm}$ \\
\hline
\end{tabular}

The obtained relative permeability from the developed semi-analytical model is compared to that found by FEM in Fig. 8 good agreements are obtained. One can see the high saturation of the machine especially in the stator yoke and the rotor bridge where the relative permeability is less than 50 .

Another presentation of obtaining results is shown in Fig. 9, where the magnitude of $\boldsymbol{B}$ in all machines regions is plotted, the comparison between analytical and numerical results improve the model accuracy regarding the local saturation which can be observed in inner/outer rotor bridge, stator yoke, and partial part of stator/rotor teeth.

Different performances versus rotor position are presented in Figs. 10-12. The simulation is done with two different initial rotor position values, viz., $\theta_{r s 0}=0$ at no-load and $\theta_{r s 0}=\pi / 2 p$ at full-load, and different value of supply current $(0,10$, and $20 A)$. Fig. 10 shows the cogging torque for no-load condition, and the electromagnetic torque for on load condition. For the no-/full-load condition, the induced magnetic flux linkage per phase and the back-EMF or voltage are given in Figs. 11-12. The obtained results confirm the accuracy of the proposed semi-analytical model considering both amplitude and waveform. 


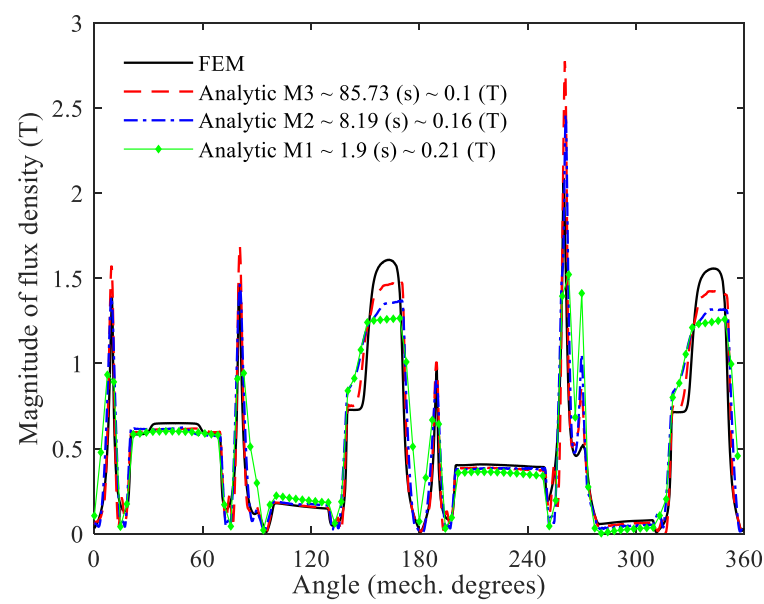

(a)

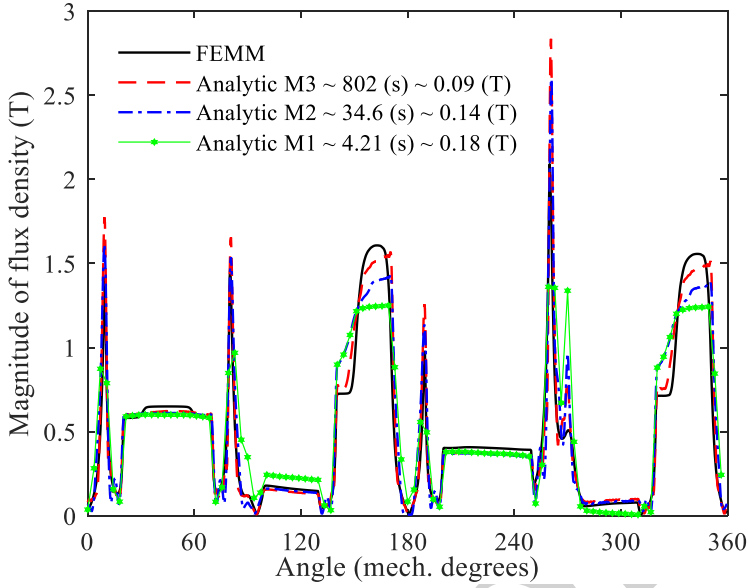

(b)

Fig. 4. Magnitude of $\boldsymbol{B}$ in the middle of the air-gap (i.e., Region I) for on load condition I=20 A: (a) one harmonic per E-SD and (b) three harmonics per E-SD (i.e., Analytic mesh computational time (s) RMS error (T)).

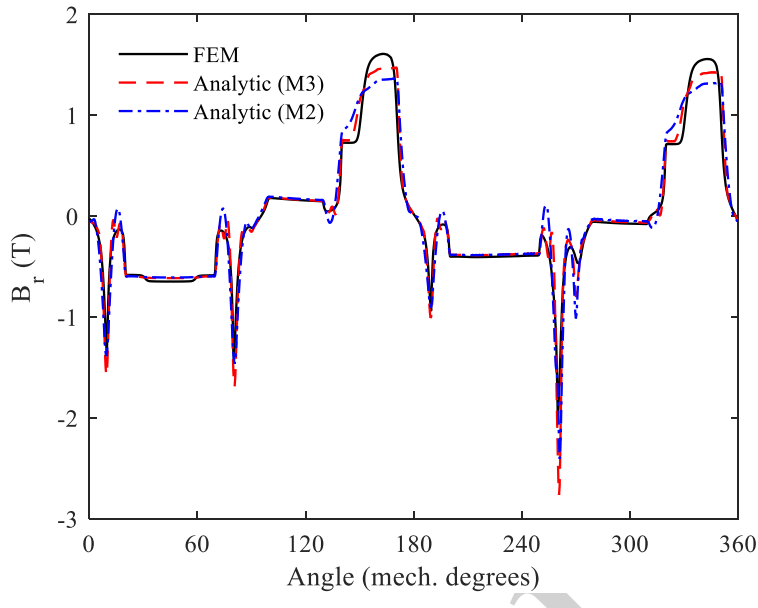

(a)

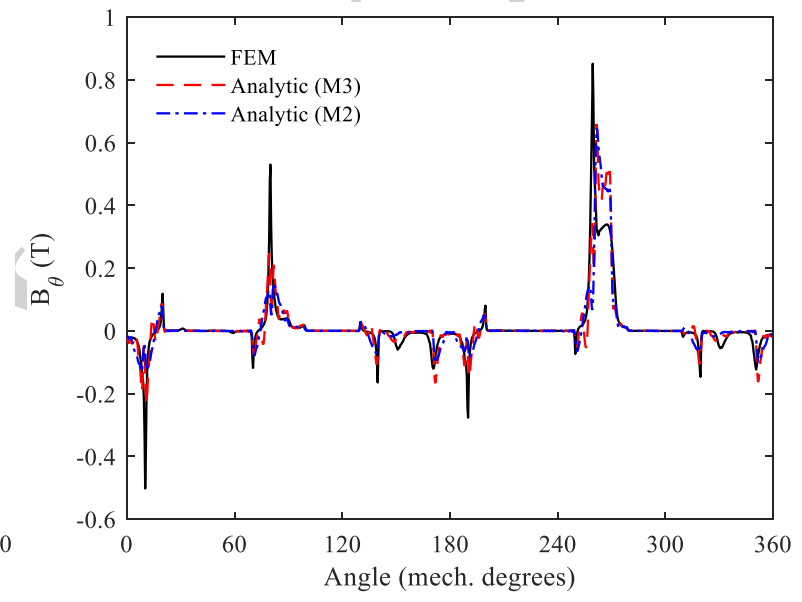

(b)

Fig. 5. Waveform of $\boldsymbol{B}$ in the middle of the air-gap for on load condition $\mathrm{I}=20 \mathrm{~A}$ : (a) $r$ - and (b) $\theta$-component.

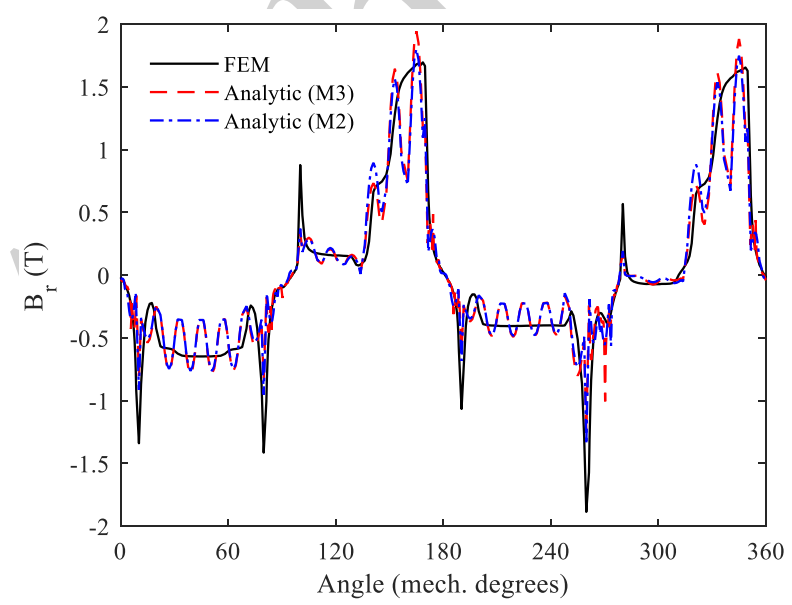

(a)

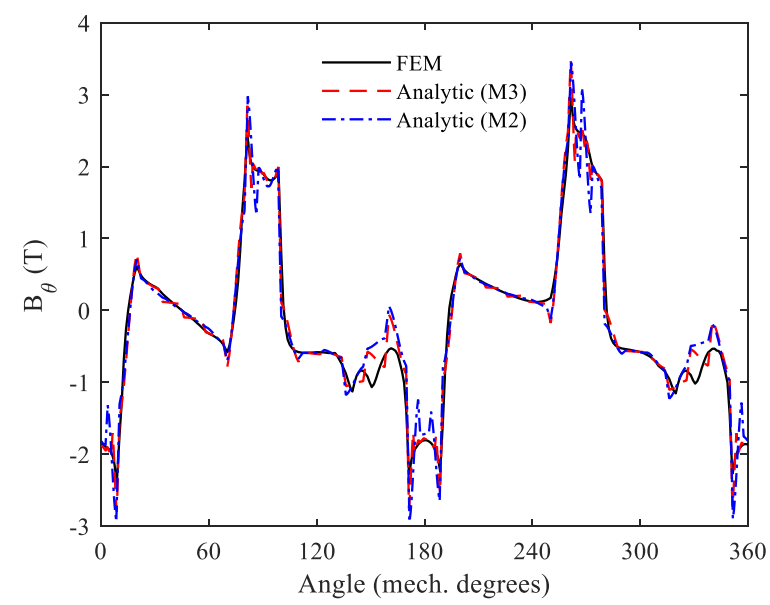

(b)

Fig. 6. Waveform of $\boldsymbol{B}$ in the middle of the outer rotor bridge for on load condition $\mathrm{I}=20 \mathrm{~A}$ : (a) $r$ - and (b) $\theta$-component. 


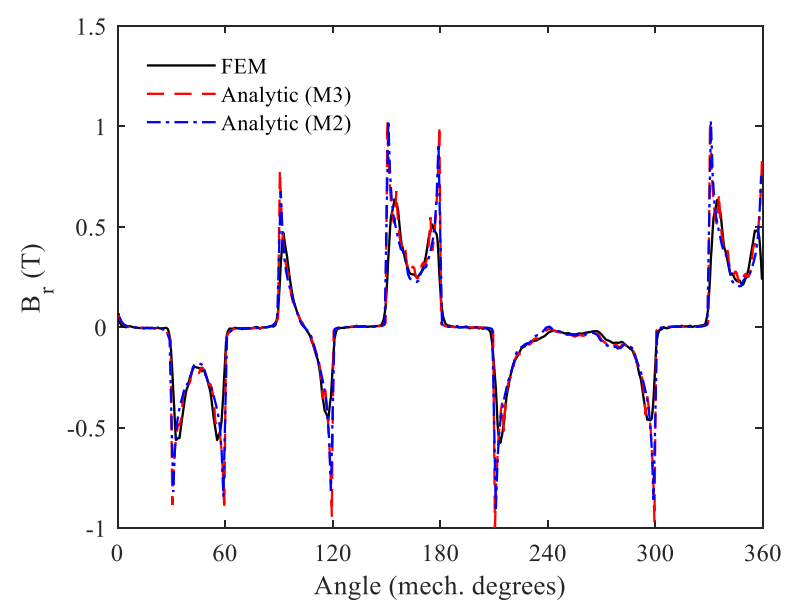

(a)

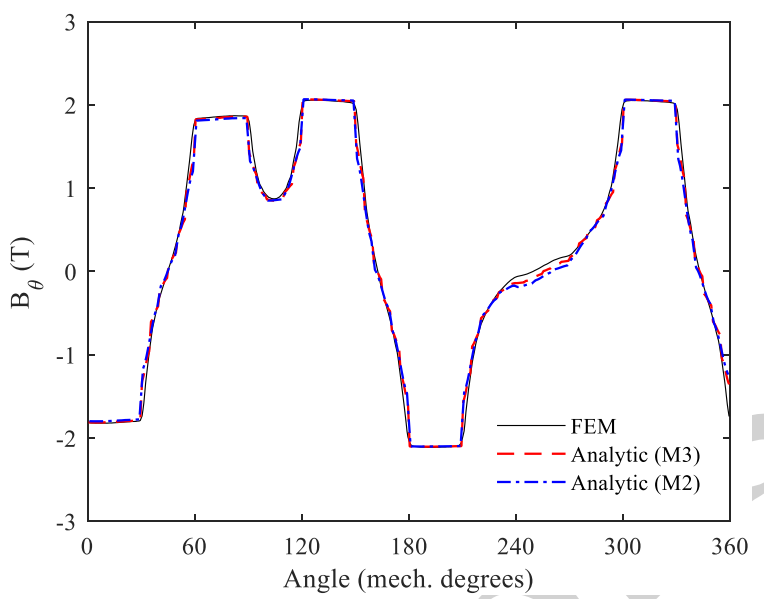

(b)

Fig. 7. Waveform of $\boldsymbol{B}$ in the middle of the stator yoke for on load condition $\mathrm{I}=20 \mathrm{~A}$ : (a) $r$ - and (b) $\theta$-component.

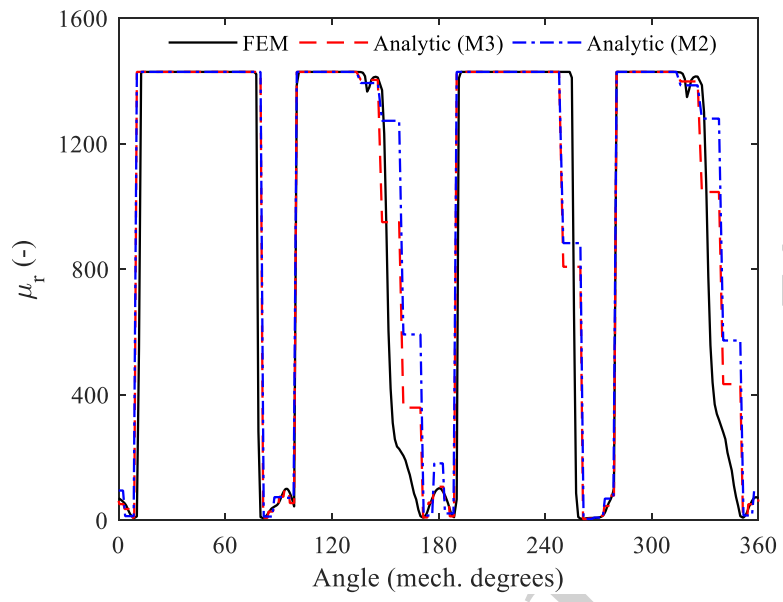

(a)

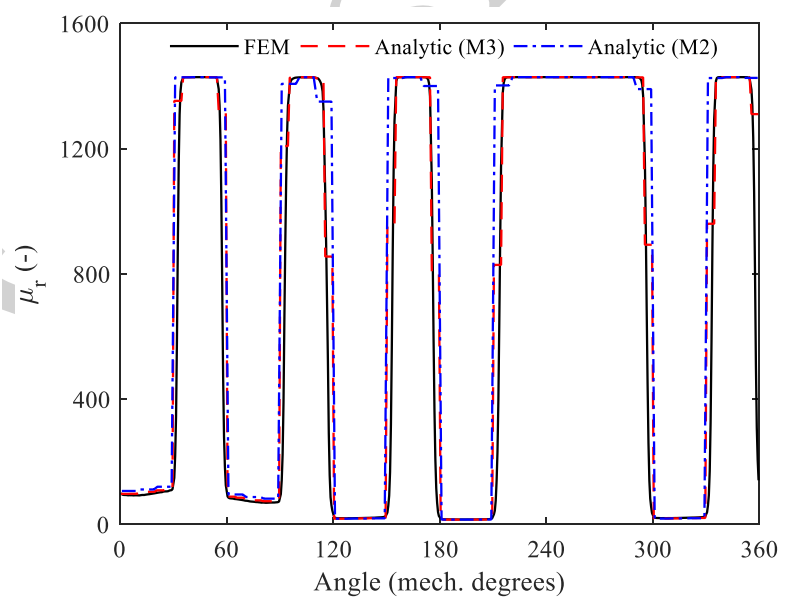

(b)

Fig. 8. Waveform of relative permeability in the middle of (a) the rotor bridge and (b) stator yoke for on load condition I=20 A.

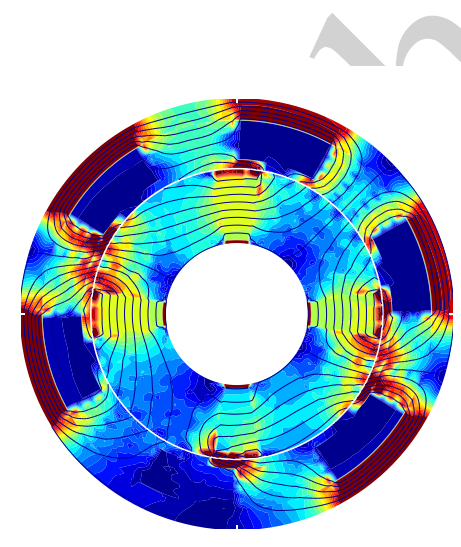

(a)
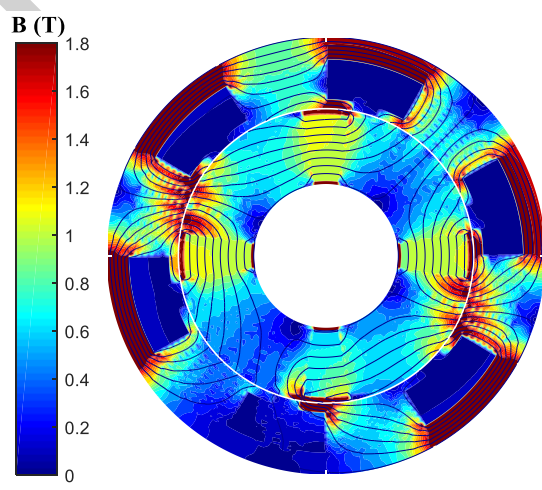

(b)

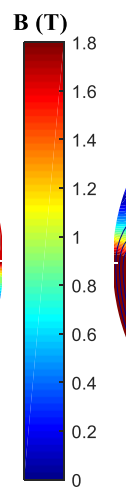

(1)

Fig. 9. Flux density inside the machine for on load condition $\mathrm{I}_{\mathrm{m}}=20 \mathrm{~A}$ : (a) analytic with mesh M2, (b) analytic with mesh M3, and (b) FEM 


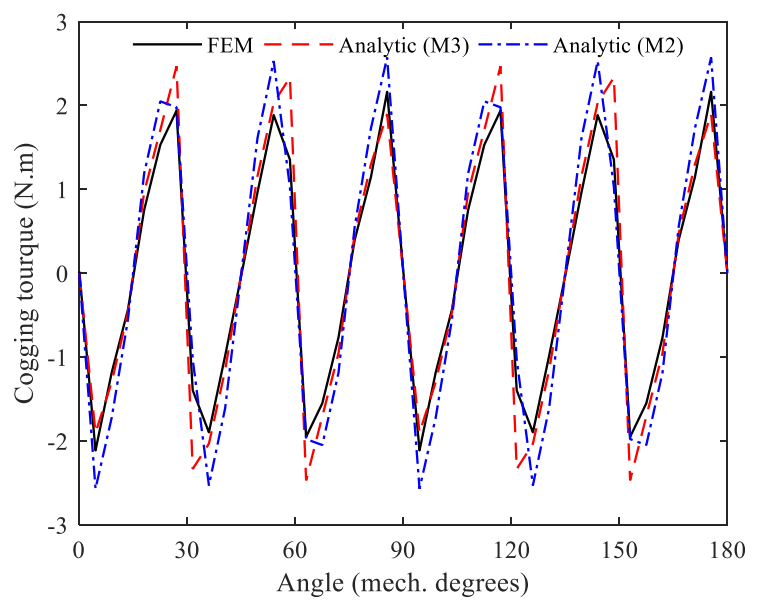

(a)

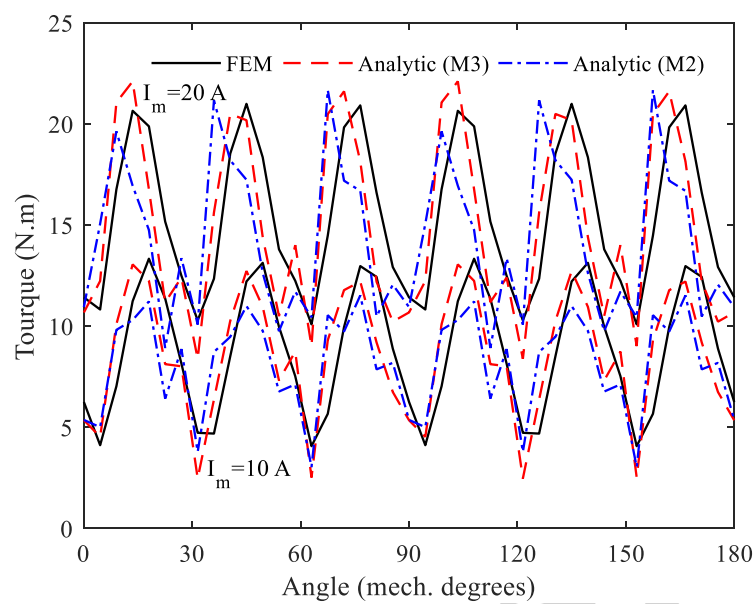

(b)

Fig. 10. Waveform of (a) cogging torque (b) electromagnetic torque for on load condition I=20 10 A.

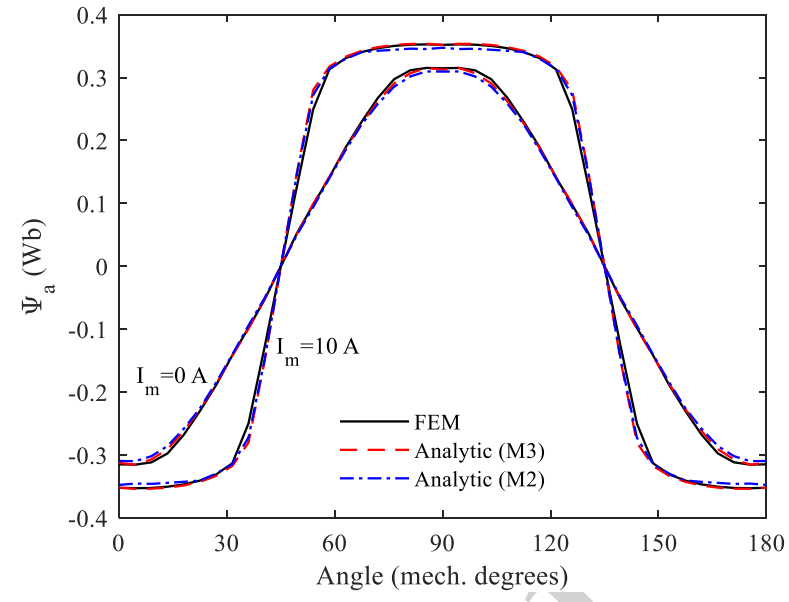

(a)

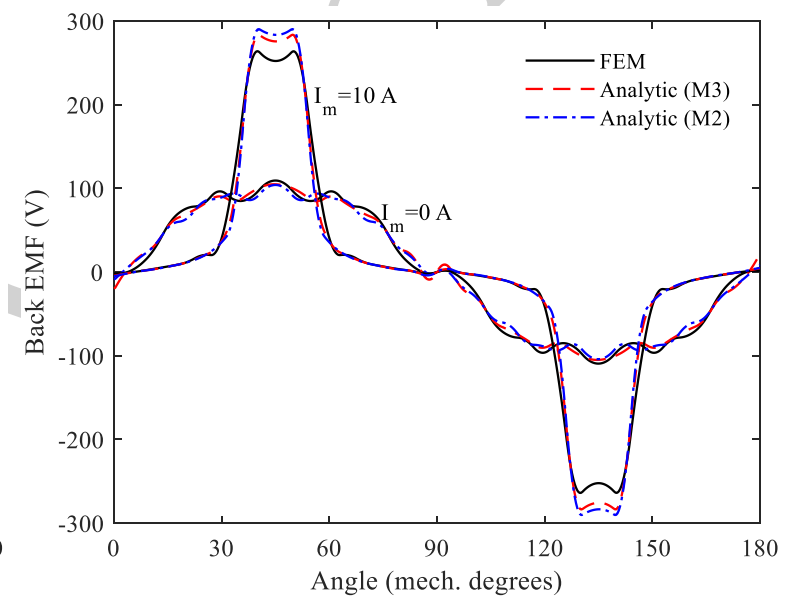

(b)

Fig. 11. Waveform of the: (a) magnetic flux linkage and (b) back-EMF at no-load for $\theta_{r s}=0$.

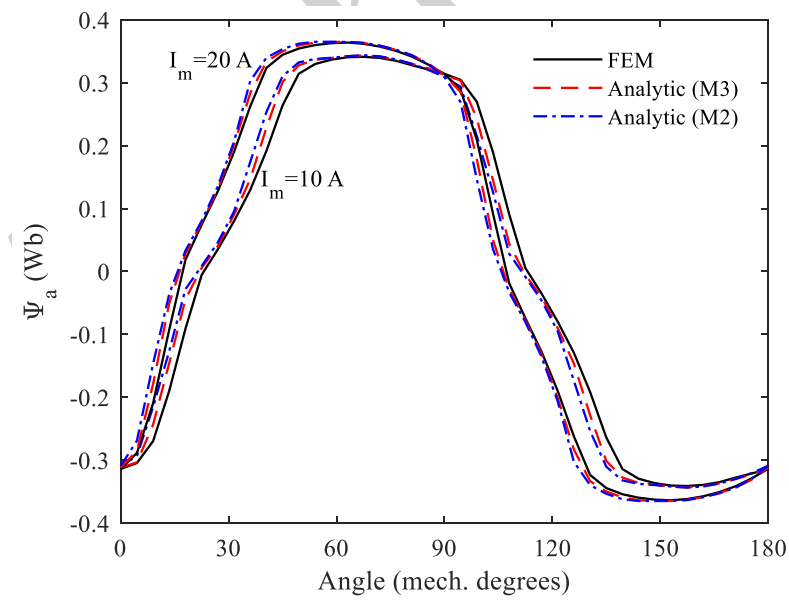

(a)

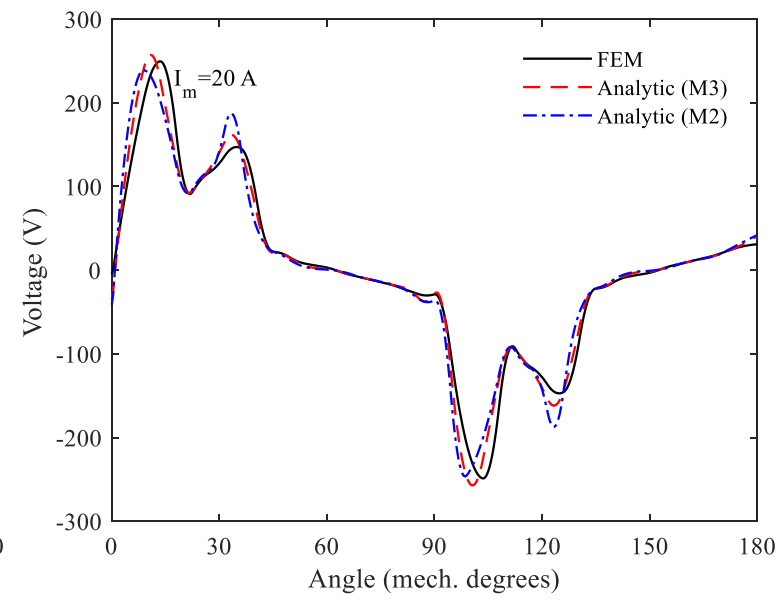

(b)

Fig. 12. Waveform of the: (a) magnetic flux linkage and (b) voltage at full-load for $\theta_{r s}=2 \pi / p$. 


\section{CONCLUSION}

In this paper, we have proposed an improved semi-analytical model based on the 2-D subdomain technique in polar coordinates $(r, \theta)$ for the rotating electrical machine. The model has been applied to the STPMM. In this approach, the rotor and the stator regions are divided into E-SDs which are characterized by general solutions to the first harmonic of magnetostatic Maxwell's equations. The ICs are performed in both directions (i.e., $r$ - and $\theta$-edges). The local saturation effect has been taken into account in the electromagnetic modeling. NR iterative algorithm has been used for nonlinear magnetic field analysis.

In addition to considering local saturation, one of the largest advantages of the discussed approach is its compatibility with various geometries, viz., with(out) bridge, with(out) semi-closed, one(double) layer..., the only change to make is the particular solution association for each E-SD.

In comparison with numerical method, the 2-D semi-analytical results are in good agreement with the ones obtained by 2-D FEM. However, the obtained of accuracy results need computation time more than FEM. Therefore, future research should focus on the optimization of the proposed model.

\section{APPENDIX A}

The $B(H)$ and $v(\bar{B})$ curves for the ferromagnetic material (i.e., type of steel M27_24G) used in this proposed model are shown in Fig. A-1. The specific parameters used herein are shown in Table A-I.

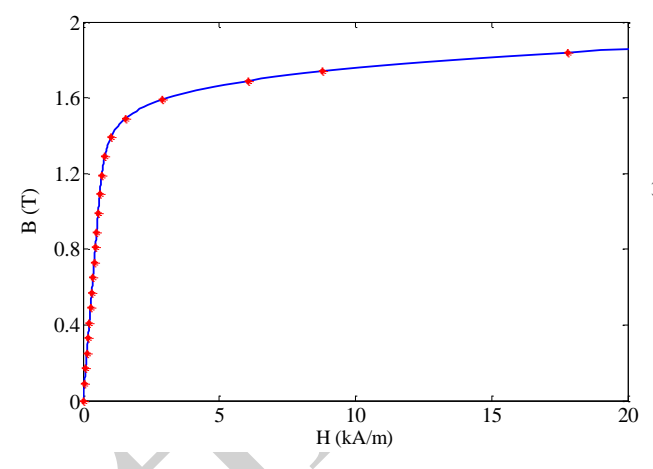

(a)

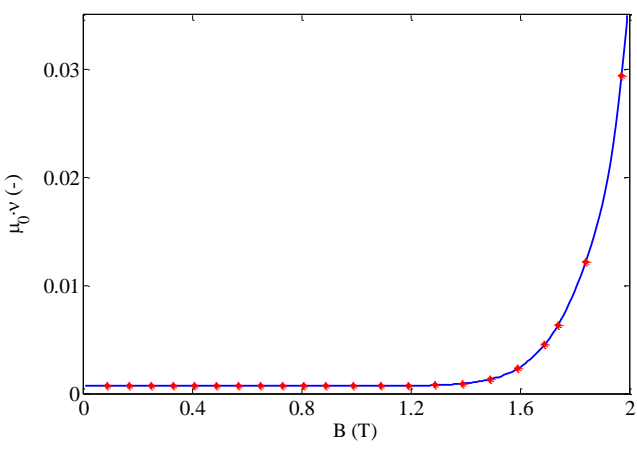

(b)

Fig. A-1. (a) $B(H)$ and (b) $v(\bar{B})$ curve.

TABLE A-I. PARAMETERS FOR RELUCTIVITY CURVE FIT EQUATION

\begin{tabular}{|c|c|c|c|}
\hline $\boldsymbol{q}$ & $\boldsymbol{m}_{\boldsymbol{q}}$ & $\boldsymbol{n}_{\boldsymbol{q}}$ & $\boldsymbol{a}_{\boldsymbol{q}}$ \\
\hline $\boldsymbol{1}$ & 1.8874 & 15.0467 & 1.001 \\
\hline $\boldsymbol{2}$ & 2.1440 & 65.8347 & 1.0006 \\
\hline $\mathbf{3}$ & 1.9433 & 99.9533 & 1.0005 \\
\hline
\end{tabular}




\section{APPENDIX B}

- Magnetic vector potential ICs:

The sub-matrices $\left\{\Lambda^{11} ; \Lambda^{12} ; \Lambda^{13} ; \Gamma^{1}\right\}$ are defined from the ICs between Region I, II and III at $r=R_{r}$ and $r=R_{s}$ as:

$$
\begin{aligned}
& A_{z I}\left(R_{r}, \theta\right)=A_{z I I}^{K_{r}, l}\left(R_{r}, \theta\right) \\
& A_{z I}\left(R_{s}, \theta\right)=A_{z I I I}^{1, l}\left(R_{s}, \theta\right)
\end{aligned}
$$

Fourier series expansion of (B-1) gives

$$
\begin{aligned}
& B_{1}^{K_{r}, l}+B_{2}^{K_{r}, l} \ln \left(R_{r}\right)+\left.A_{z I I}^{p K_{r}, l}\right|_{R_{r}}=\frac{1}{a_{l}} \int_{\alpha_{l}-\frac{a_{l}}{2}}^{\alpha_{l}+\frac{a_{l}}{2}} A_{z l}\left(R_{r}, \theta\right) \cdot d \theta \\
& B_{3}^{K_{r}, l} R_{r}^{\vartheta_{r} l}+B_{4}^{K_{r}, l} R_{r}^{-\vartheta_{r l}}=\frac{2}{a_{l}} \int_{\alpha_{l}-\frac{a_{l}}{2}}^{\alpha_{l}+\frac{a_{l}}{2}} A_{z l}\left(R_{r}, \theta\right) \cos \left[\vartheta_{r l}\left(\theta-\alpha_{l}+\frac{a_{l}}{2}\right)\right] d \theta
\end{aligned}
$$

Fourier series expansion of (B-2) gives

$$
\begin{aligned}
& C_{1}^{1, l}+C_{2}^{1, l} \ln \left(R_{s}\right)+\left.A_{z=I I}^{p 1, l}\right|_{R_{s}}=\frac{1}{b_{l}} \int_{\beta_{l}-\frac{b_{l}}{2}}^{\beta_{l}+\frac{b_{l}}{2}} A_{z I}\left(R_{s}, \theta\right) d \theta \\
& C_{3}^{1, l} R_{s}^{\vartheta_{s l}}+C_{4}^{1, l} R_{s}^{-\vartheta_{s l}}=\frac{2}{b_{l}} \int_{\beta_{l}-\frac{b_{l}}{2}}^{\beta_{l}+\frac{b_{l}}{2}} A_{z I}\left(R_{s}, \theta\right) \cos \left[\vartheta_{s l}\left(\theta-\beta_{l}+\frac{b_{l}}{2}\right)\right] d \theta
\end{aligned}
$$

The sub-matrices $\left\{\Lambda^{22} ; \Gamma^{2}\right\}$ are defined from the ICs between the E-SDs in Region II in addition to Dirichlet's BC at $r=R_{\text {int }}$ as:

$$
\begin{aligned}
& A_{z I I}^{k, l}\left(R r_{k+1}, \theta\right)=A_{z I I}^{k+1, l}\left(R r_{k+1}, \theta\right) \\
& A_{z I I}^{k, l}\left(r, \alpha_{l}+\frac{a_{l}}{2}\right)=A_{z I I}^{k, l+1}\left(r, \alpha_{l+1}-\frac{a_{l+1}}{2}\right) \\
& A_{z I I}^{1, l}\left(R_{i n t}, \theta\right)=0
\end{aligned}
$$

Fourier series expansion of (B-7) gives

$$
\begin{aligned}
& {\left[\begin{array}{l}
B_{1}^{k, l}+B_{2}^{k, l} \ln \left(R r_{k+1}\right) \\
\ldots+\left.A_{z I I}^{p k, l}\right|_{R_{k+1}}
\end{array}\right]=\left[\begin{array}{l}
B_{1}^{k+1, l}+B_{2}^{k+1, l} \ln \left(R r_{k+1}\right) \\
\ldots+\left.A_{z I I}^{p k+1, l}\right|_{R_{k+1}}
\end{array}\right]} \\
& B_{3}^{k, l} R r_{k+1}^{\vartheta_{n}}+B_{4}^{k, l} R r_{k+1}^{-\vartheta_{r l}}=B_{3}^{k+1, l} R r_{k+1}^{\vartheta_{r l}}+B_{4}^{k+1, l} R r_{k+1}^{-\vartheta_{n l}}
\end{aligned}
$$

The developed of (B-8) gives 


$$
\begin{aligned}
& \int_{R_{k+1}}^{R_{R_{k+1}}}\left[\begin{array}{l}
B_{1}^{k, l+1}-B_{1}^{k, l}+\left(B_{2}^{k, l+1}-B_{2}^{k, l}\right) \ln (r) \\
\ldots+B_{z l}^{p, l l}-A_{z}^{k, l+1} r_{r(l+1)}^{p, l}+B_{4}^{k, l+1} r^{-\vartheta_{r}(l+1)} \\
\ldots+B_{3}^{k, l} r^{\vartheta_{r l}}+B_{4}^{k, l} r^{-\vartheta_{r l}}
\end{array}\right] \sin \left(\lambda_{r k} \ln \left(\frac{r}{R r_{k}}\right)\right) \frac{d r}{r} \\
& \cdots+\frac{\ln \left(R r_{k+1} / R r_{k}\right)}{2}\left[B_{6}^{k, l+1} \sinh \left(-\lambda_{r k} a_{l}\right)-B_{5}^{k, l} \sinh \left(\lambda_{r k} a_{l}\right)\right]=0
\end{aligned}
$$

The developed of (B-9) gives

$$
\begin{aligned}
& B_{1}^{1, l}+B_{2}^{1, l} \ln \left(R_{i n t}\right)+\left.A_{z I l}^{p 1, l}\right|_{R_{i n t}}=0 \\
& B_{3}^{1, l} R_{i n t}^{\vartheta_{r l}}+B_{4}^{1, l} R_{i n t}^{-\vartheta_{r l}}=0
\end{aligned}
$$

The sub-matrices $\left\{\Lambda^{33} ; \Gamma^{3}\right\}$ are defined from the ICs between the E-SDs in Region III in addition to Dirichlet's BC at $r=R_{\text {ext }}$ as:

$$
\begin{aligned}
& A_{z I I I}^{k, l}\left(R s_{k+1}, \theta\right)=A_{z I I I}^{k+1, l}\left(R s_{k+1}, \theta\right) \\
& A_{z I I I}^{k, l}\left(r, \beta_{l}+\frac{b_{l}}{2}\right)=A_{z I I I}^{k, l+1}\left(r, \beta_{l+1}-\frac{b_{l+1}}{2}\right) \\
& A_{z I I I}^{K_{s}, l}\left(R_{e x t}, \theta\right)=0
\end{aligned}
$$

Fourier series expansion of (B-15) gives

$$
\begin{aligned}
& {\left[\begin{array}{l}
C_{1}^{k, l}+C_{2}^{k, l} \ln \left(R s_{k+1}\right) \\
\ldots+\left.A_{z I I I}^{p k, l}\right|_{R s_{k+1}}
\end{array}\right]=\left[\begin{array}{l}
C_{1}^{k+1, l}+C_{2}^{k+1, l} \ln \left(R s_{k+1}\right) \\
\ldots+\left.A_{z I I I}^{p k+1, l}\right|_{R s_{k+1}}
\end{array}\right]} \\
& C_{3}^{k, l} R s_{k+1}^{9_{s+1}}+C_{4}^{k, l} R s_{k+1}^{-\vartheta_{s l}}=C_{3}^{k+1, l} R s_{k+1}^{9_{s l}}+C_{4}^{k+1, l} R s_{k+1}^{-\vartheta_{s l}}
\end{aligned}
$$

The developed of (B-16) gives

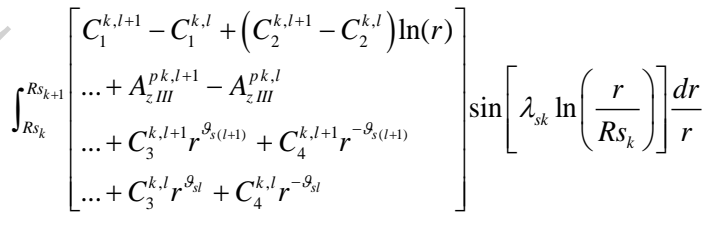

$$
\begin{aligned}
& \cdots+\frac{\ln \left(R s_{k+1} / R s_{k}\right)}{2}\left[C_{6}^{k, l+1} \sinh \left(-\lambda_{s k} b_{l}\right)-C_{5}^{k, l} \sinh \left(\lambda_{s k} b_{l}\right)\right]=0
\end{aligned}
$$

The developed of (B-17) gives

$$
\begin{aligned}
& C_{1}^{K_{s}, l}+C_{2}^{K_{s}, l} \ln \left(R_{e x t}\right)+\left.A_{z I I I}^{p K_{s}, l}\right|_{R_{e x t}}=0 \\
& C_{3}^{K_{s}, l} R_{e x t}^{9_{s l}}+C_{4}^{K_{s}, l} R_{e x t}^{-y_{s} l}=0
\end{aligned}
$$

- Field intensity ICs:

The sub-matrices $\left\{\Lambda^{41} ; \Lambda^{42} ; \Lambda^{43} ; \Gamma^{4}\right\}$ are defined from the ICs between Region I, II and III at $r=R_{r}$ and $r=R_{s}$ as: 


$$
\begin{aligned}
& H_{\theta I}\left(R_{r}, \theta\right)=H_{\theta I I}^{K_{r}, l}\left(R_{r}, \theta\right) \\
& H_{\theta I}\left(R_{s}, \theta\right)=H_{\theta I I I}^{1, l}\left(R_{s}, \theta\right)
\end{aligned}
$$

Fourier series expansion of (B-23) gives

$$
\begin{aligned}
& -\frac{A 2_{0}}{\mu_{0} R_{r}}=\frac{1}{2 \pi} \sum_{l=1}^{L_{r}}\left[\int_{\alpha_{l}-\frac{a_{l}}{2}}^{\alpha_{l}+\frac{a_{l}}{2}} H_{\theta I l}^{K_{r}, l}\left(R_{r}, \theta\right) d \theta\right]
\end{aligned}
$$

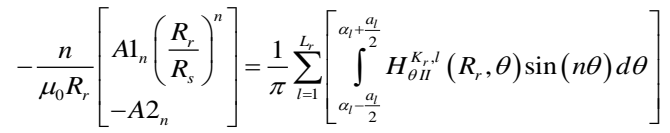

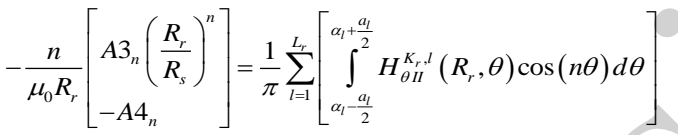

Fourier series expansion of (B-24) gives

$$
\begin{aligned}
& -\frac{A 2_{0}}{\mu_{0} R_{s}}=\frac{1}{2 \pi} \sum_{l=1}^{L_{s}}\left[\int_{\beta_{l}-\frac{b_{l}}{2}}^{\beta_{l}+\frac{b_{l}}{2}} H_{\theta I I I}^{1, l}\left(R_{s}, \theta\right) d \theta\right] \\
& \frac{n}{\mu_{0} R_{s}}\left[\begin{array}{l}
A 2_{n}\left(\frac{R_{s}}{R_{r}}\right)^{-n} \\
\cdots-A 1_{n}
\end{array}\right]=\frac{1}{\pi} \sum_{l=1}^{L_{s}}\left[\int_{\beta_{l}-\frac{b_{l}}{2}}^{\beta_{t}+\frac{b_{l}}{2}} H_{\theta I I I}^{1, l}\left(R_{s}, \theta\right) \sin (n \theta) d \theta\right]
\end{aligned}
$$

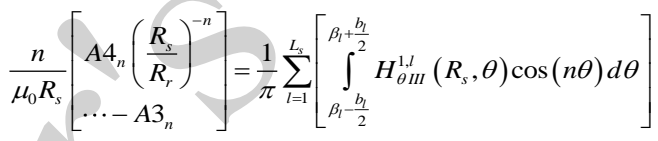

The sub-matrices $\left\{\Lambda^{52} ; \Gamma^{5}\right\}$ are defined from the ICs between the E-SDs in Region II as:

$$
\begin{aligned}
& H_{\theta I I}^{k, l}\left(R r_{k+1}, \theta\right)=H_{\theta I I}^{k+1, l}\left(R r_{k+1}, \theta\right) \\
& H_{r I I}^{k, l}\left(r, \alpha_{l}+\frac{a_{l}}{2}\right)=H_{r I I}^{k, l+1}\left(r, \alpha_{l+1}-\frac{a_{l+1}}{2}\right)
\end{aligned}
$$

Fourier series expansion of (B-31) gives

$$
\frac{v_{I I}^{k, l}}{v_{I I}^{k+1, l}}\left[\begin{array}{l}
\left.\int_{\alpha_{l}-\frac{a_{l}}{2}}^{\alpha_{t}+\frac{a_{l}}{2}} \frac{\partial A_{z I I}^{r k, l}}{\partial r}\right|_{r=R_{k+1}} \\
\cdots+\frac{a_{l} B_{2}^{k, l}}{R r_{k+1}}
\end{array}\right]=\left[\begin{array}{l}
\int_{\alpha_{l}-\frac{a_{l}}{2}}^{\alpha_{l}+\frac{a_{l}}{2}} \frac{\partial z_{z I}^{r k+1, l}}{\partial r} \\
\cdots+\frac{a_{l} B_{2}^{k+1, l}}{R r_{k+1}}
\end{array}\right]
$$




$$
\begin{gathered}
\int_{\alpha_{l}-\frac{a_{l}}{2}}^{\alpha_{l}+\frac{a_{l}}{2}}\left[\left.\frac{v_{I I}^{k, l}}{v_{I I}^{k+1, l}} \frac{\partial A_{z I I}^{r k, l}}{\partial r}\right|_{R_{k+1}}-\left.\frac{\partial A_{z I I}^{r+1, l}}{\partial r}\right|_{R_{r_{k+1}}}\right] \cos \left[\vartheta_{r l}\left(\theta-\alpha_{l}+\frac{a_{l}}{2}\right)\right] \\
\cdots+\frac{\pi}{a_{l} R r_{k+1}}\left[\begin{array}{l}
\left(\frac{v_{I l}^{k, l}}{v_{I I}^{k+1, l}} B_{3}^{k, l}-B_{3}^{k+1, l}\right) R r_{k+1}^{\vartheta_{r l}} \\
\cdots-\left(\frac{v_{I I}^{k, l}}{v_{I I}^{k+1, l}} B_{4}^{k, l}-B_{4}^{k+1, l}\right) R r_{k+1}^{-\vartheta_{n}}
\end{array}\right]=0
\end{gathered}
$$

where

$$
\begin{aligned}
& \frac{\partial A_{z I I}^{r k, l}}{\partial r}=\lambda_{r k}\left\{B_{5}^{k, l} \sinh \left[\lambda_{r k}\left(\theta-\alpha_{l}+\frac{a_{l}}{2}\right)\right]\right. \\
& \left.\cdots+B_{6}^{k, l} \sinh \left[\lambda_{r k}\left(\theta-\alpha_{l}-\frac{a_{l}}{2}\right)\right]\right\} \cos \left[\lambda_{r k} \ln \left(\frac{r}{R r_{k}}\right)\right]
\end{aligned}
$$

The developed of (B-32) gives

$$
\frac{v_{I I}^{k, l}}{v_{I I}^{k, l+1}}\left[\begin{array}{l}
B_{5}^{k, l} \cosh \left(\lambda_{r k} a_{l}\right) \\
\cdots+B_{6}^{k, l}
\end{array}\right]=\left[\begin{array}{l}
B_{6}^{k, l+1} \cosh \left(-\lambda_{r k} a_{l}\right) \\
\cdots+B_{5}^{k, l+1}
\end{array}\right]
$$

The sub-matrices $\left\{\Lambda^{63} ; \Gamma^{6}\right\}$ are defined from the ICs between E-SDs in Region III as:

$$
\begin{aligned}
& H_{\theta I I I}^{k, l}\left(R s_{k+1}, \theta\right)=H_{\theta I I I}^{k+1, l}\left(R s_{k+1}, \theta\right) \\
& H_{r I I I}^{k, l}\left(r, \beta_{l}+\frac{b_{l}}{2}\right)=H_{r I I I}^{k, l+1}\left(r, \beta_{l+1}-\frac{b_{l+1}}{2}\right)
\end{aligned}
$$

Fourier series expansion of (B-37) gives

$$
\begin{aligned}
& \frac{V_{I I}^{k, l}}{V_{I I I}^{k+l, l}}\left[\begin{array}{l}
\left.\int_{\beta_{l} \frac{b_{l}}{2}}^{\beta_{l}+\frac{b_{l}}{2}} \frac{\partial A_{z I I}^{r k, l}}{\partial r}\right|_{r=R_{s_{k+1}}} \\
\cdots+\frac{b_{l} C_{2}^{k, l}}{R s_{k+1}}
\end{array}\right]=\left[\begin{array}{l}
\left.\int_{\beta_{l} \frac{b_{l}}{2}}^{\beta_{l}+\frac{b_{l}}{2}} \frac{\partial A_{z I I I}^{r k+1, l}}{\partial r}\right|_{r=R_{k+1}} \\
\cdots+\frac{b_{l} C_{2}^{k+1, l}}{R s_{k+1}}
\end{array}\right] \\
& \int_{\beta_{l}-\frac{b_{l}}{2}}^{\beta_{\beta_{l}}+\frac{b_{l}}{2}}\left[\left.\frac{v_{I I I}^{k, l}}{v_{I I}^{k+1, l}} \frac{\partial A_{z I I}^{r k, l}}{\partial r}\right|_{R_{S_{k+1}}}-\left.\frac{\partial A_{z I I I}^{r k+, l}}{\partial r}\right|_{R_{S_{k+1}}}\right] \cos \left[\vartheta_{s l}\left(\theta-\beta_{l}+\frac{b_{l}}{2}\right)\right] \\
& \cdots+\frac{\pi}{b_{l} R s_{k+1}}\left[\begin{array}{l}
\left(\frac{v_{I I}^{k, l}}{v_{I I I}^{k+1, l}} C_{3}^{k, l}-C_{3}^{k+1, l}\right) R s_{k+1}^{9_{s}} \\
\cdots-\left(\frac{v_{I I}^{k, l}}{v_{I I I}^{k+1, l}} C_{4}^{k, l}-C_{4}^{k+1, l}\right) R s_{k+1}^{9_{s l}}
\end{array}\right]=0
\end{aligned}
$$

where

$$
\begin{aligned}
& \frac{\partial A_{z l l l}^{r k, l}}{\partial r}=\lambda_{s k}\left\{C_{s}^{k, l} \sinh \left[\lambda_{s k}\left(\theta-\beta_{l}+\frac{b_{l}}{2}\right)\right]\right. \\
& \left.\cdots+C_{6}^{k, l} \sinh \left[\lambda_{s k}\left(\theta-\beta_{l}-\frac{b_{l}}{2}\right)\right]\right\} \cos \left[\lambda_{s k} \ln \left(\frac{r}{R s_{k}}\right)\right]
\end{aligned}
$$

The developed of (B-38) gives 


$$
\frac{v_{l l}^{k, l}}{v_{I l l}^{k, l+1}}\left[\begin{array}{l}
C_{5}^{k, l} \cosh \left(\lambda_{s k} b_{l}\right) \\
\cdots+C_{6}^{k, l}
\end{array}\right]=\left[\begin{array}{l}
C_{6}^{k, l+1} \cosh \left(-\lambda_{s k} b_{l}\right) \\
\cdots+C_{5}^{k, l+1}
\end{array}\right]
$$

\section{APPENDIX C}

It can be seen from field intensity ICs in rotor region that the sub-matrix $\Lambda^{42}\left(b^{\text {rotor }}\right)$ can be written as:

and

$$
\Lambda^{42}\left(b^{\text {rotor }}\right) \cdot b^{\text {rotor }}=\left[\begin{array}{lllll} 
& & & & \\
\cdots & \xi_{2}^{k, l} v_{I I}^{k, l} & \cdots & \xi_{6}^{k, l} v_{I I}^{k, l} & \cdots \\
& & \vdots & &
\end{array}\right]\left[\begin{array}{c}
\vdots \\
B_{2}^{k, l} \\
\vdots \\
B_{6}^{k, l} \\
\vdots
\end{array}\right]
$$

where

$$
v_{I I}^{k, l}=f\left(\bar{B}_{I I}^{k, l}\right)
$$

with $\bar{B}_{I I}^{k, l}$ is the mean value of field density in the $\mathrm{E}-\mathrm{SD} \Omega_{I I}^{k, l}$, in which it is approximate as

$$
\bar{B}_{I I}^{k, l}=\sqrt{\left(\bar{B}_{r I I}^{k, l}\right)^{2}+\left(\bar{B}_{\theta I I}^{k, l}\right)^{2}}
$$

where

$$
\begin{aligned}
& \bar{B}_{r I I}^{k, l}=\frac{1}{S_{\Omega_{l i}^{k l}}} \int_{R_{r_{k}}}^{R_{r_{k+1}}^{\alpha_{l}}} \int_{\alpha_{l}-\frac{a_{l}}{2}}^{\alpha_{l}+\frac{a_{l}}{2}} B_{r I I}^{k, l} r \cdot d r \cdot d \theta \\
& \bar{B} \theta \text { II }=\frac{1}{S_{\Omega_{I I}^{k, l}}^{k, l}} \int_{R_{r_{k}}}^{R_{r_{k+1}}} \int_{\alpha_{l}-\frac{a_{l}}{2}}^{\alpha_{l}+\frac{a_{l}}{2}} B_{\theta I I}^{k, l} r \cdot d r \cdot d \theta
\end{aligned}
$$

with $S_{\Omega_{I l}^{k, l}}=a_{l}\left(R r_{k+1}^{2}-R r_{k}^{2}\right) / 2$ is the surface of the $\mathrm{E}-\mathrm{SD} \Omega_{I I}^{k, l}$.

According to solution given in (8), the expansion of (C-4) and (C-5) gives

$$
\bar{B}_{r I I}^{k, l}=\frac{1}{S_{\Omega_{l i}^{k, l}}^{k}}\left[q_{1} B_{3}^{k, l}+q_{2} B_{4}^{k, l}+q_{3}\left(B_{5}^{k, l}+B_{6}^{k, l}\right)\right]
$$




$$
\bar{B}_{\theta I I}^{k, l}=\frac{1}{S_{\Omega_{l i}^{k, l}}}\left[q_{4} B_{2}^{k, l}+q_{5}\left(B_{5}^{k, l}-B_{6}^{k, l}\right)\right]
$$

where

$$
\left\{\begin{array}{l}
q_{1}=\frac{-2}{1+\vartheta_{r l}}\left(R r_{k+1}^{1+\vartheta_{r l}}-R r_{k}^{1+\vartheta_{r l}}\right) \\
q_{2}=\frac{-2}{1-\vartheta_{r l}}\left(R r_{k+1}^{1-\vartheta_{r l}}-R r_{k}^{1-\vartheta_{r l}}\right) \\
q_{3}=\sinh \left(\lambda_{r k} a_{l}\right)\left(e^{\ln \left(R r_{k+1} / R_{k}\right)}+1\right) \frac{\lambda_{r k} R r_{k}}{1+\lambda_{r k}^{2}} \\
q_{4}=a_{l}\left(R r_{k+1}-R r_{k}\right) \\
q_{5}=\left(1-\cosh \left(\lambda_{r k} a_{l}\right)\right)\left(e^{\ln \left(R r_{k+1} / R r_{k}\right)}+1\right) \frac{R r_{k}}{1+\lambda_{r k}^{2}}
\end{array}\right.
$$

Then

$$
\frac{\partial v_{I I}^{k, l}}{\partial B_{\bullet}^{k, l}}=\left.\partial v_{I I}^{k, l}\right|_{\bar{B}_{I I}^{k, l}}\left(\frac{\bar{B}_{r I I}^{k, l}}{\bar{B}_{I I}^{k, l}} \frac{\partial \bar{B}_{r I I}^{k, l}}{\partial \bar{B}_{\bullet}^{k, l}}+\frac{\bar{B}_{\theta I I}^{k, l}}{\bar{B}_{I I}^{k, l}} \frac{\partial \bar{B}_{\theta I I}^{k, l}}{\partial \bar{B}_{\bullet}^{k, l}}\right)
$$

where

$$
\partial v(\bar{B})=\frac{1}{\mu_{0}}\left[\frac{Q \sum_{q=1}^{Q} \frac{\left(\bar{B} / m_{q}\right)^{n_{q}-1}}{m_{q}}\left(\left(\bar{B} / m_{q}\right)^{n_{q}}+a_{q}^{n_{q}}\right)^{1 / n_{q}-1}}{\left(\sum_{q=1}^{Q}\left(\left(\bar{B} / m_{q}\right)^{n_{q}}+a_{q}^{n_{q}}\right)^{1 / n_{q}}\right)^{2}}\right]
$$

with the same method the sub-matrices $\left\{\partial \Lambda^{52} / \partial b^{\text {rotor }} ; \partial \Lambda^{43} / \partial c^{\text {stator }} ; \partial \Lambda^{63} / \partial c^{\text {stator }}\right\}$ can be calculated.

\section{REFERENCES}

[1] J. Jin, “The Finite Element Method in Electromagnetic”, 2nd ed., John Wiley \& Sons, Inc.: New York, NY, USA, 2002.

[2] G. D. Smith, "Numerical solution of partial differential equations: Finite difference methods - Third edition, Clarendon press - Oxford, 1985.

[3] H. Vansompel, P. Sergeant, L. Dupré, "A multilayer 2-D-2-D coupled model for eddy current calculation in the rotor of an axial-flux PM machine," IEEE Trans. Energy Conv., vol. 27, no. 3, pp. 784-791, Sep. 2012.

[4] R. Benlamine, F. Dubas, S-A. Randi, D. Lhotellier, and C. Espanet, "3-D numerical hybrid method for PM eddy-current losses calculation: Application to axial-flux PMSMs,” IEEE Trans. Magn., vol. 51, no. 7, 8106110, July 2015.

[5] F. Dubas, and C. Espanet, "Analytical solution of the magnetic field in permanent-magnet motors taking into account slotting effect: No-load vector potential and flux density calculation,” IEEE Trans. Magn., vol. 45, no. 5, pp. 2097-2109, May 2009.

[6] K. Boughrara, R. Ibtiouen, and T. Lubin, "Analytical prediction of magnetic field in parallel double Excitation and spoke-type permanent-magnet machines accounting for tooth-tips and shape of polar pieces," IEEE Trans. Magn., vol. 48, no. 7, pp. 2121-2137, Jul. 2012. 
[7] T. Lubin, S. Mezani, and A. Rezzoug, "Two-dimensional analytical calculation of magnetic field and electromagnetic torque for surfaceinset permanent-magnet motors,” IEEE Trans. Magn., vol. 48, no. 6, pp. 2080-2091, Jun. 2012.

[8] P. Liang, F. Chai, Y. Li, and Y. Pei, "Analytical prediction of magnetic field distribution in spoke-type permanent-magnet synchronous machines accounting for bridge saturation and magnet shape,” IEEE Trans. Ind. Elect., vol. 64, no. 5, pp. 3479-3488, May 2017.

[9] K. Boughrara, N. Takorabet, R. Ibtiouen, O. Touhami, and F. Dubas, "Analytical analysis of cage rotor induction motors in healthy, defective, and broken bars conditions," IEEE Trans. Magn., vol. 51, no. 2, Feb. 2015, Art. ID 8200317.

[10] L. Roubache, K. Boughrara, and R. Ibtiouen, "Analytical electromagnetic analysis of multi-phases cage rotor induction motors in healthy, broken bars and open phases conditions," Progress In Electromagnetics Research B, vol. 70, pp. 113-130, Oct. 2016.

[11] K. Boughrara, F. Dubas, and R. Ibtiouen, "2-D analytical prediction of eddy currents, circuit model parameters, and steady-state performances in solid rotor induction motors," IEEE Trans. Magn., vol. 50, no. 12, Dec. 2014, Art. ID 7028214.

[12] R.L.J. Sprangers, J.J.H. Paulides, B.L.J. Gysen, and E.A. Lomonova, "Magnetic saturation in semi-analytical harmonic modeling for electric machine analysis,” IEEE Trans. Magn., vol. 52, no. 2, Feb. 2016, Art. ID 8100410.

[13] K.Z. Djelloul, K. Boughrara, F. Dubas, and R. Ibtiouen, "Nonlinear analytical prediction of magnetic field and electromagnetic performances in switched reluctance machines," IEEE Trans. Magn., vol. 53, no. 7, Jul. 2017, Art. ID 8107311.

[14] F. Dubas, and K. Boughrara, "New scientific contribution on the 2-D subdomain technique in Cartesian coordinates: Taking into account of iron parts," Math. Comput. Appl., vol. 22, no. 1, pp. 17, Feb. 2017 (doi: 10.3390/mca22010017).

[15] L. Roubache, K. Boughrara, F. Dubas, and R. Ibtiouen, "Semi-analytical modeling of spoke-type permanent-magnet machines considering the iron core relative permeability: Subdomain technique and Taylor polynomial," Progress In Electromagnetics Research $B$, vol. 77, pp. 85-101, Jul. 2017.

[16] F. Dubas, and K. Boughrara, "New scientific contribution on the 2-D subdomain technique in polar coordinates: Taking into account of iron parts," Math. Comput. Appl., vol. 22, no. 4, pp. 42, Oct. 2017 (doi: 10.3390/mca22040042).

[17] L. Roubache, K. Boughrara, F. Dubas, and R. Ibtiouen, "New Subdomain Technique for Electromagnetic Performances Calculation in Radial-Flux Electrical Machines Considering Finite Soft-Magnetic Material Permeability,” IEEE Trans. Magn. 2018 (doi: 0.1109/TMAG.2017.2785254).

[18] M. Curti, J.J.H. Paulides, and E.A. Lomonova, "An overview of analytical methods for magnetic field computation," in Proc. EVER, Grimaldi Forum, Monaco, 31 Mar.-02 Apr., 2015

[19] E. Devillers, J. Le Besnerais, T. Lubin, M. Hecquet, and J. P. Lecointe, “A review of subdomain modeling techniques in electrical machines: Performances and applications," in Proc. ICEM, Lausanne, Switzerland, 04-07 Sep. 2016.

[20] D.C. Meeker. (Apr. 1, 2009). Finite Element Method Magnetics ver. 4.2. [Online]. Available: http://www.femm.info.

[21] J. Cale, S. D. Sudhoff, and J. Turner, “An improved magnetic characterization method for highly permeable materials,” IEEE Trans. Magn., vol. 42, no. 8, pp. 1974-1981, Aug. 2006.

[22] K. Fujiwara, T. Nakata, N. Okamoto, and K. Muramatsu, "Method for determining relaxation factor for modified Newton-Raphson method", IEEE Trans. Magn., vol. 29, no. 2, pp. 1962-1965, March 1993. 